\title{
ECO-ECO Recycling Models and Application of their Principles into the Circular Economy
}

\author{
Alena Kusá ${ }^{1, *}$, Tomáš Fašiang ${ }^{1}$, Pavel Gežík ${ }^{2}$, Michal Greguš ${ }^{3}$ \\ ${ }^{1}$ Department of Marketing Communication, University of Ss. Cyril and Methodius \\ in Trnava, Faculty of Mass Media Communication, Nam. J. Herdu 2917 01, \\ Trnava, Slovakia, alena.kusa@ucm.sk, tomas.fasiang@ucm.sk \\ ${ }^{2}$ Department of Operational Research and Econometrics, University of Economics \\ in Bratislava, Faculty of Business Informatics, Dolnozemská cesta 1, 85235 \\ Bratislava, Slovak Republic, pavel.gezik@euba.sk \\ ${ }^{3}$ Department of Strategy and Business, Faculty of Management, Comenius \\ University in Bratislava, Odbojárov 10, 82005 Bratislava, Slovak Republic; \\ michal.gregusml@fm.uniba.sk \\ *Corresponding author
}

\begin{abstract}
Today's global economy shows that particular markets have become much more saturated and heterogenous than ever before. They are dominated by consumer's individual needs whose behaviour is changing under the influence of external or internal factors. Therefore, global consumption is on a constant growth. When taking into account long-term sustainability as well as our moral commitment to nature and its resources, we need to focus on environmental protection and consider reusing materials within a production process. One of the solutions is to focus on green innovations, which are applicable in the circular economy and apply ecological and economic models of initial recycling into a production process. The main goal of our paper is to define a model of application of eco-eco principles in the circular economy by providing a specific view on the model aspect of procurement of production materials from recycling as well as presenting various possibilities on how to meet eco-eco goals of businesses which are based upon circular economy principles. The main output of the paper is the proposal of three variants how to approach product recycling models while emphasising their specificities and usability.
\end{abstract}

Keywords: modeling; stock management; reverse logistics; recycling; circular economy 


\section{Introduction}

The $21^{\text {st }}$ Century has experienced a significant environmental impact of the society. This is mainly due to a growing number of inhabitants, which is directly linked to uncontrolled material consumption as well as waste production (described in more detail by Adamisin et al., 2018; Peracek et al., 2018). In order to eliminate negative human impact on nature and protect the environment, brand new green innovations have been introduced in the last decades of the $21^{\text {st }}$ Century. The benefits of innovations in this field cannot be perceived only through economic parametres because economic indices are determining factors for their implementation. These innovations have to be understood in a broader context because apart from their fundamental protection function, they may also reflect a need for sustainable development of the whole society and therefore be a key competitive advantage. The application of the circular economy concept is one of those systems (Benešová, 2010; Srovnaliková et al., 2020).

The amount of waste increases by $3 \%$ each year. Suitable life conditions depend directly on the way that raw materials are exploited (Stasiak-Betlejwska, 2015). People exploit these valuable resources to transform them into various products, construct infrastructure, buildings, electronic appliances or produce energy, etc.

Environmental and economic problems are directly linked to the overproduction of waste and therefore these questions are sensitively perceived among countries. Products happen not to be fit for reuse in the production and the society is unable to process such high amounts of waste on landfills (Bod'ová, Gajarská, Bad’urová, 2004). The above-mentioned circular economy concept could foster economic growth and influence the economy by promoting a positive attitude to environmental protection (Razminiene, 2019; Horecký, 2018). It aims at creating a new innovative process or a business model where already used materials or spare parts are returned into the production process to avoid wasting of valuable materials in economies. The constant demand for non-renewable resources generates pressure and damages the environment. However, it is crucial to pay attention to marketing communication to make the general public aware of these environmental concepts (Darnadyová, 2014). The connection of environmental and economic principles for the whole perception of economic models is often referred to as „ECO-ECO“. This term derives from the modeling approach „EcoEco Models“, i.e. from the English word eco(nomy)-eco(logy), i.e. economicecological model. These refer to economic situations that tend to meet not only economic but also ecological goals. It is often the ecological aspect of these models which is governed by specific statutes or various social requirements businesses have to comply with (Jašková, 2019).

The eco-eco approach helps solve not only simple but also more complicated economic situations of individual business entities within a particular economy. Businesses are able to adapt their production accordingly, either purchase 
materials and goods or deal with transportation issues. Households are able to apply these principles when satisfying their needs and in the procurement of enviromentally friendly goods and services. Such purchase is referred to as ecoeco behaviour of a consumer as this one does not take into consideration the price, but other factors as well, such as environmental impact.

Businesses may use eco-eco optimalisation models when handling transport or transfer of materials necessary for ensuring production as well as delivery of ready goods (Zaušková, Rezníčková, 2020; Oláh et al., 2018). They can also be used in models with considerable material inputs where material or product recycling is welcome. Last but not least: we can not omit legislation, which paves the way for the implementation of the eco-eco approach in economic processes. The current economic trend leads to unsustainable exploitation of materials and energies resulting in a radical reduction of both renewable and non-renewable resources. Such a decline along with growing amounts of waste leads to serious ecological problems. Therefore it has been necessary to enact statutes forcing producers to think over their economic as well as environmental production aspects. Producers have had to consider economic and ecological ways how to ensure the transportation of a product to a customer and what is more, how to dispose of products after their expiry.

\section{Theoretical Aspects of the Subject Matter}

As we have mentioned in the introduction, the eco-eco principles can be looked at from both the production and consumer sphere or all through economic processes (Dul'ová, Spišáková, Mura, Gontkovičová, Hajduová, 2017). No matter if a business or a consumer is involved, it always has to consist of two parts - the economic and the ecological one. The subject matter is often discussed in two main areas - production and transport. These two parts have an impact on a producer on how to select materials, handle the transportation, purchase materials or how to transport them to a customer (Nascimento, Alencastro, Quelhas, Caiado, Garza-Reyes, Lona, Tortorella, 2019). They also have an impact on a consumer who is interested in what materials have been used and what means of transport has been selected. As these assumptions can not be exclusively economic, corresponding statutes have recently been adopted to handle emissions and waste disposal.

\subsection{Integrated Product Policy and a Consumer}

Consumers use various product materials on a daily basis. By their diversity, quality and functional ability they represent certain prospects and wealth and what is more, they influence the quality of life. Growing consumption is both a direct 
and an indirect source of environmental pollution and depletion of natural resources. As most products are traded on a global or regional level, the company should achieve balanced development of its worldwide production while emphasizing quality of the global environment for future generations as enacted in the Declaration on the Environment and Development (Rio de Janeiro, 1992). One of the possibilities how to aspire to such development is to focus on a new growth paradigm and wealth distribution as well as competitiveness which can be achieved through more environmentally friendly products. Wealth refers not only to economic growth but also to limitation of exploitation of natural resources or preservation and improvement of the quality of the environment by eliminating negative environmental impacts or environmental and health-related risks (the Government Office of the Slovak Republic, 2019). Such wealth is directly linked to evolution of the society on different levels. Its main objective - to launch more environmentally friendly products in the market - has to be promoted by producers and consumers as a fundamental philosophy that has to be adopted in the initial product design phase at all points of sale. As soon as the product has been introduced in the market, there is not much we can do about any improvements hereon. In that case, all efforts of research and development workers or costs incurred may be vain if consumers do not buy or use these products in an environmentally friendly way for any reasons whatsoever.

Enhancing the environmental concept of production policy, promoting public debate and consumer orientation are all incorporated into the integrated production policy, i.e. the policy of modification and innovation of environmental behaviour of production systems for the purpose of eliminating negative environmental impact of products in course of their whole life cycle - from the exploitation of raw materials through production, distribution and use up to waste disposal (Bod'ová, Gajarská, Bad'urová, 2004). Based on the aforementioned, it is important to enhance the identification of environmental awareness of consumers in purchasing everyday products. According to the research we carried out and which helped us to identify key factors influencing consumer purchasing behaviour, three key attributes have been defined - those that represent basic determinants having an impact on our daily purchase. By applying the factor analysis, we may assume that the decisive factors influencing a Slovak consumer when purchasing everyday products are as follows:

- factor 1 - origin, quality and product environmental footprint,

- factor 2 - product affordability,

- factor 3 - marketing communication and its impact in the point of sale.

The first factor states that at first, a Slovak consumer takes into consideration the product quality in relation to its origin and environmental footprint. The second factor indicates that the product price plays a role in the purchase and a consumer tries to buy affordable products. The third factor points to the fact that a Slovak 
consumer takes a decision directly at the moment of purchase and is influenced by a set of marketing activities in the point of sale.

Table 1

Identification of factors influencing purchase of everyday products

\begin{tabular}{|l|c|c|c|}
\hline Attributes & Factor 1 & Factor 2 & Factor 3 \\
\hline Packaging & & 0.279 & 0.392 \\
\hline Packaging size & & 0.677 & \\
\hline Affordable price & -0.213 & $0-717$ & 0.182 \\
\hline Volume discount & 0.227 & 0.653 & \\
\hline Environmentally friendly product & 0.533 & & \\
\hline Product quality & 0.494 & -0.192 & 0.121 \\
\hline Product made in Slovakia & 0.654 & 0.15 & 0.124 \\
\hline Product content & 0.709 & & -0.134 \\
\hline Brand & 0.29 & -0.366 & 0.348 \\
\hline Country of origin & 0.787 & & \\
\hline Having an option to return the product & & & 0.415 \\
\hline Marketing in the point of sale & & 0.128 & 0.767 \\
\hline A special offer & & 0.39 & 0.686 \\
\hline
\end{tabular}

Source: private source, 2019

Based upon these facts and tendencies we may assume that ecological features of a product or its packaging have a preference impact on a consumer's buying process. Consumer's eco-eco behaviour means a consumer will purchase only on the basis of the price while taking into consideration a product's environmental impact. When selecting a product, a consumer looks at distance and emissions occurring in the course of product purchase. In order to attract a consumer and be different from competitors, businesses apply various marketing tools and innovations to reach diversity and build consumer loyalty. And these is the main role of eco-eco principles. It is often not only a voluntary decision as in many cases businesses are forced to do so by legislation, which is further discussed in another chapter. The fundamental aspect should always be an attempt to fulfill economic objectives connected with corporate social responsibility and environmental protection. In this field one may focus on the ecological and economic approach of consumer purchasing behaviour, which is set to put pressure on producers the same way as the legislation does. One of the possibilities of how to succeed in today's competitive environment is applying consumer-oriented eco-eco innovations. These innovations represent one of the most effective tools how to maintain and accelerate economic development and ensure business prosperity on both a local and a global market (Mura, Havierniková, Machová, 2017; Mucha et al., 2018). Their key feature is to offer an added value which has a considerable impact on consumer requirements during the consumption process. ECO-ECO innovations connect elimination of the 
emissions and costs, which is a priority in today's world of corporate social responsibility and consumer perception. These are the elements that are set to enhance consumer loyalty and satisfaction.

\subsection{Recency of Eco-Eco Principles and Legislative Pressure in this Field}

The eco-eco approach is rather usual for transport models or models dealing with the shortest transportation routes, i.e. the legislation for air pollution and emissions. Or models dealing with material issues, which is a preferred solution for material and product recycling (Gežík, Brezina, 2009). Therefore, we may observe certain social pressure on ecological thinking in process optimising. This is enacted in the corresponding legislation which governs all sets of criteria in connection with optimising or application of the ECO-ECO approach. It is mainly the European Union Legislation which is often referred to when forming ECOECO models and represents a basis for implementation of ecological objectives into economically-oriented processes. Every year 1.3 billion of waste are produced in the EU with approx. 40 million tons of toxic waste, which accounts for 3.5 tons per head and is still rising. It is estimated that if no changes are implemented, our waste production will have increased by almost $45 \%$ by 2020 compared to 1995. (the European Commission - Environment, [online]. Available at: http://ec.europa.eu/environment/waste/index.htm [07-06-2019]. As we have already mentioned, the core principle of the ecological approach is minimising waste, for example by reducing fuel consumption. Production of exhaust fumes is directly linked to over-consumption and therefore, the lower consumption, the fewer emissions into the air. $14.78 \mathrm{~kg}$ of air are needed for complete combustion of $1 \mathrm{~kg}$ of petrol (3.4kg of oxygen) while producing $3.15 \mathrm{CO}_{2}$. Reduction of $\mathrm{CO}_{2}$ emissions is a key ecological objective of our society.

The European Community legislation (the EU) is enacted in many different statutes - Directives of the European Parliament or the European Council (hereinafter referred to as "directives“) which form a legislative basis in EU member states. These directives are split into five groups:

- Framework legislation of the European Union on waste;

- EU legislation on waste disposal policies;

- EU legislation on specific types of waste;

- Information questionnaires and legislation;

- Any corresponding by-laws.

(the European Commission - Environment, [online]. Available at: http://ec.europa.eu/environment/waste/index.htm [07-06-2019] 
According to Brezina et al. (2008) member states are committed to fulfill these objectives:

- minimising use of dangerous substances and plastics, some materials are to be gradually replaced,

- $\quad$ support of recycling-friendly design,

- $\quad$ producers can take over responsibility for ending the product life cycle, prepare a product for identification and provide information for processors regarding suitable recycling,

- $\quad$ both households and public areas have to be equipped with collection points for recycling labelled free-of-charge,

- producers have to create and finance proper systems for ensuring appropriate processing and product recycling and they become responsible herefore in collection points.

The European Community Directives are one of the most effective tools for fighting environmental pollution and emissions. These directives involve methodological guidelines of the Ministry of Environment in Slovak language. These directives and guidelines contain various restrictions and producers/importers/sellers of products (mostly electroproducts) are obliged to finance, ensure and participate in collection and liquidation of electric waste and packaging waste or they may refer to various restrictions in connection with emissions and limitations of the use of some categories of vehicles.

\section{Objective, Material and Methodology}

The main objective of the paper is to provide a model for eco-eco principles and their use within the circular economy by offering a specific view of the model aspect of material procurement from recycling. It is a sort of demonstration of these principles through mathematical modeling with one criteria function and that is when two parts of an eco-eco model, i.e. the economic and the ecological one are interconnected through balance in order to find the extreme of this connected function. When applying principles of eco-eco modeling of recycling in the circular economy, we focus on how to return products into their life cycle (Savaskan, et al. 2004), process of inventory level and return (Schulz-Ferretti, 2008) as well as the character of inventory (Dyckhoff, et al. 2003).

\subsection{Eco-Eco Model}

Mathematical modeling or linear programming enables clear recording and draws from the principle of aggregation of target criteria for model creation as 
mentioned above, i.e. one objective consists of two parts. These two parts involve a particular balance referring to model preferences. The aggregation principle of target criteria for tasks with various purpose-made functions draws from the assumption that the aggregate purpose-made function equals to:

$f_{0}(x)=\sum_{k=1}^{s} v_{k} f_{k}(x)=\sum_{k=1}^{s} v_{k} \sum_{i=1}^{n} \sum_{j=1}^{n} c_{i j k} x_{i j}$, where $f_{k}$, for $k \in$ $(1,2, \ldots, s)$ represents specific purpose-made functions with an ecological objective of the set $s$ representing all objectives of the Eco-eco model. Specific targets involve the balance $v_{k}$ which equals to $\sum_{k=1}^{S} v_{k}=1$. Particular functions consist of variables $x_{i j}$ which represent connection among specific places and their corresponding evaluation $c_{i j k}$ for $i, j \in(1,2, \ldots, n)$ referring to the set of all places interconnected with optimization. $c_{i j k}$ equals to $c_{i j k}=c_{i j k}$ with the connection between places $i$ and $j$ where $c_{i j k}=0$ and if the connection occurs within specific places, the value $\infty$ shall be applied.

In view of $s$ direct demonstration of the circular economy, the model aspect is described through recycling processes while providing an ideal basis for explaining ,the circle“ (Darnadyová, 2014). As mentioned above, eco-eco principles in models are mostly used in two main areas:

- transportation - models for transportation optimisation where the economic part consists of minimising transport costs and ecological minimising of emissions,

- material procurement - models connected to production optimisation including complex tasks where specific parts of eco-eco models are interlinked.

Most of the models focus on transportation optimisation or looking for the shortest ways for minimising transport costs or transport time, i.e. this reduction does not involve economic objectives. Minimum distance is an economic objective because it is connected with fuel consumption. This is closely linked to emissions as the higher consumption, the higher emissions. Consequently, each particular transport model minimising the distance or fuel consumption is said to be an eco-eco model. For this reason, the following chapters mainly deal with recycling and procurement of material for production through recycling, where the economic part of the eco-eco model lies in minimising costs for material procurement and the ecological one in minimising waste.

\subsection{Eco-Eco Recycling Model Aspect}

From the view of the circular economy, material procurement for production by recycling is about finding the ways how this material may be returned from consumers to manufacturers (EIS, 2019). 


\section{Ways of Return}

In a truly integrated supply chain everyone in the supply chain can track a product as it moves forward through the channel (Selvefors, Rexfelt, Renstrom, Stromberg, 2019). While there are very few supply chains that really function this well, there are virtually none that work in reverse. Most firms cannot track returns within their own organization, much less somewhere outside of their firm (Hajduová, Andrejkovič, Mura, 2014). Depending on the reason of return ways the products are returned change as well. These ways depend on the subjects which are processing the return. Based on the relationship between manufacturer and retailer we can assume four possible ways of product return back to the manufacturer. First, is the closed-loop supply chain where the manufacturer collecting used products is the retailer itself, the second is when the products are returned directly to the manufacturer, which is not the retailer. In the third way, the products are returned through the retailer that is collecting used products and the fourth when the return is facilitated by a third party. These ways of product return are displayed in the figure below.
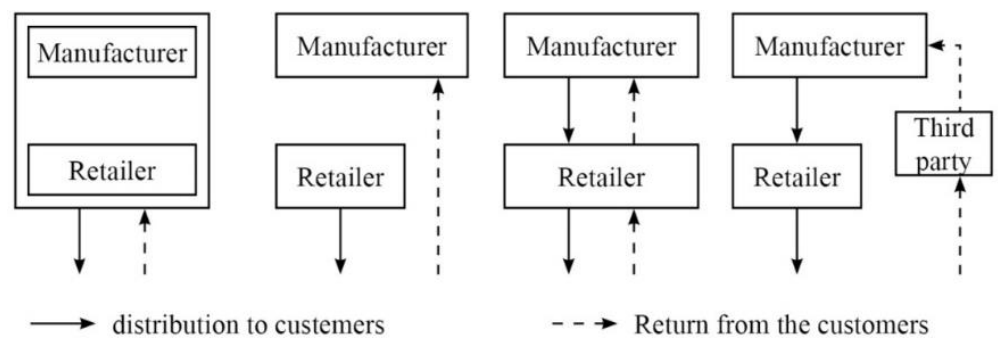

$--\rightarrow$ Return from the customers

Figure 1

Ways of return

Source: Savaskan et al. 2004

It is important to remark that not only the final customers can return the products, but retailers and distributors as well. The process of reception of the returned products implies some different activities of revision and control that determine the actual state of the product. Only after that; it is possible to determine the best strategy of how to dispose of products, in the most cost-effective manner (Radu, 2018).

\section{Material Requirements Planning}

In the circle economy, as the consequence of the return flow, the inventory level between new component replenishment's is no longer necessarily decreasing but may increase (Razminiene, 2019). This loss of monotonicity significantly complicates the underlying mathematical models. A possible starting point for a closer analysis of this aspect is the cash balancing models comprising in and outbound flows. There are two alternatives for fulfilling the demand that imposes an additional set of decisions to be taken. External orders and recovery have to be 
coordinated. Daniel Guide, V. et al. (2000) determine seven characteristics of the recoverable manufacturing systems that complicate the management, planning, and control of supply chain functions. They are:

- The uncertain timing and quantity of returns

- The need to balance demands with returns

- The need to disassemble the returned products

- The uncertainty in materials recovered from returned items

- The requirement for a reverse logistics network

- The complication of material matching restrictions

The problems of stochastic routings for materials for repair and remanufacturing operations are highly variable processing times. As we have mentioned before, it is possible that we have to use different parts from different returned products to produce a specific product during the remanufacturing process and also to mix them with new parts. This also complicates the production process. Guide et al (2000) shows a comparison between manufacturing and remanufacturing environment and the impact it has over the functional areas within an organization. Traditional MRP-systems are not feasible for recovery situations for several reasons. One of the main problems is the mismatch of supply and demand, due to the simultaneous release of 'wanted' and 'unwanted' components in the disassembly of returned products. A second major problem is the trade-off between reusing return components and outside procurement. In Remanufacturing, new products are manufactured using three kinds of components:

- Components that are always retrieved from return products (the quantity is unknown)

- Components that are always purchased new

- Components that can either be purchased new or retrieved from return products, depending on availability and costs.

\section{Rate of Return}

Fleischmann et al. (1997) states the following arguments, the repair operations needed to convert a returned product back to an 'as new' state depend on the actual condition of the product. This may vary from instance to instance and generally can be decided only after a number of testing and disassembly operations. Therefore, in contrast with the traditional manufacturing, no welldetermined sequence of production steps exists in remanufacturing. This exposes planning in a remanufacturing environment to a much higher uncertainty. A high level of coordination required in remanufacturing is, therefore, a result of interdependence between different parts and subassemblies. (Fleischmann, 2001). Disassembly of a returned product is not a procurement source for one part but 
releases various. The relationship between manufacturing and remanufacturing and their uncertainty describe figure, where is:

- $\quad d$ - demand

- $\quad \alpha$-rate at which products are returned to manufacturer,

- $\quad \beta$ - rate at which returned products are used,

- $\quad r t r$ - quantity of returned products, $r t r=\alpha d$

- $\quad r r$ - quantity of used returned products $r r=\alpha \beta d$

- $\quad \omega$-disposal (it means the quantity of products which are not returned or reused $), \omega=d-(r t r-r r)$

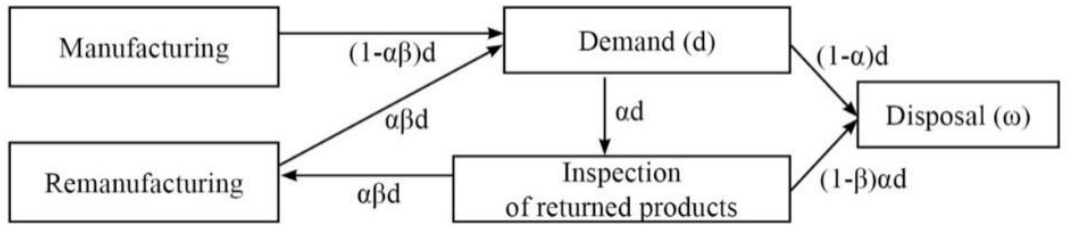

Figure 2

Manufacturing vs. Remanufacturing

Source: private source, 2019

\section{Inventory in Process of Remanufacturing}

In the process of manufacturing, there is a classic cycle stock of material needed for production and safety stock related to the fluency of production. When the returned products are used in manufacturing these two kinds of stock are supplemented by opportunity stock that is typical for remanufacturing.

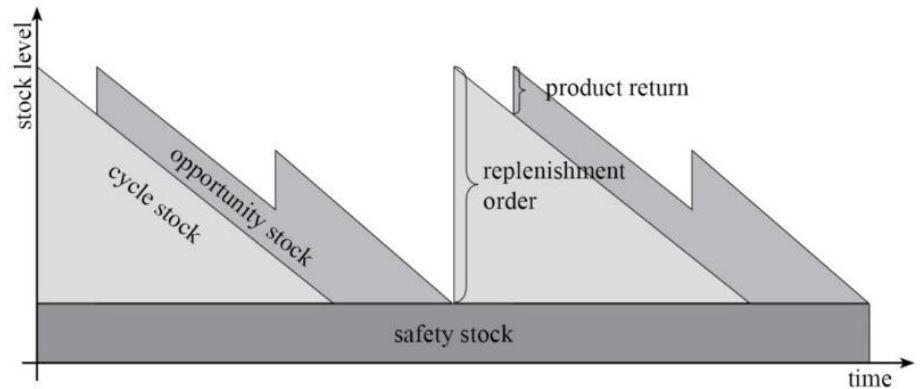

Figure 3

Material inventory

Source: Dyckhoff et al. (2003)

These opportunity stocks can be classified based on the quantity of returned products. The figure below illustrates the state where the quantity of returned products is constant in every period (a). However, the quantities of return may be 
increasing in every consecutive period, (as seen in b)) or quantity is constant in every period but is returned more frequently (c)).

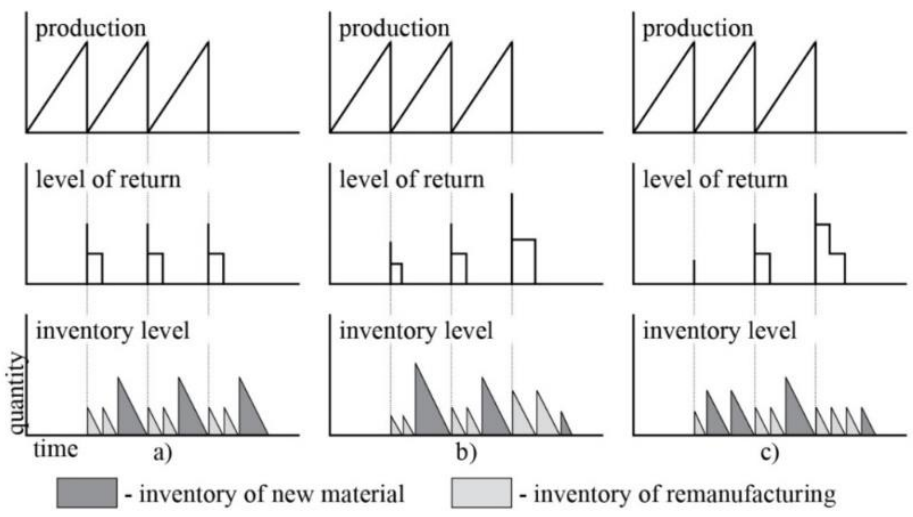

Figure 4

Inventory level in planning in a remanufacturing

Source: Schulz \& Ferretti (2008)

As we can see the return of products back to the manufacturer is effective not only in economic sense but environmentally as well. Based on these two facts the companies are focusing more on the planning of processes related to the return of the end-of-life products for their remanufacturing. Options for the returned products are numerous and include processes ranging from resale, reuse or redistribution, to repair, modification, remanufacturing, refurbishment, recycling, salvage and environmentally friendly liquidation. However, the quantity and quality of returned products is uncertain which makes material requirements planning difficult. This uncertainty led to the development of models dealing with return, quantity, and rate of return, and also inventory management connected with inventory return.

\section{The Concept of Fulfillment of Economic and Ecological Goals in the Circular Economy}

The results of the research we carried out show that businesses need to be ecofriendly. The key objective of the paper is to point to the ways how to fulfill economic and ecological goals of businesses while respecting circular economy principles. One of the possible solutions is to apply models of reverse logistics in connection with economic and environmental goals. As a result, the term of ecoeco models has been created, i.e. models following not only economic but also ecological goals. These models consider economic affordability of recycled 
materials and ecological collection of secondhand products in order to reduce the amounts of waste and protect the environment.

\subsection{The Fundamental Principle of Product Return in Time}

Obtaining returned products means that the goods had been sold to a consumer and this one returned them after having fulfilled the objective the goods had been originally purchased for. Therefore, the fundamental idea also implies purchasing material for initial production of the goods which are to be distributed and finally sold to a consumer. The consumer returns the goods to the manufacturer and this one will obtain the material suitable for further production. Product return is rather low at the beginning as not all products are consumed and returned right after production. We assume that not all products can be sold and consequently returned at the same time. Therefore, product return will be ,transferred“ to other time periods and is supposed to grow. This rise results from lower product return at its initial phase, which makes businesses purchase much more new material. These products are to be cumulated by a consumer and this one starts returning them. This principle has been described in the previous chapter and referred to as „occasional stock“ as determining its amount seems to be rather difficult due to stochastic return of recycled products. Such return of recycled products in time can be modelated by specific eco-eco models. In general, all models suppose that in course of specific time periods, such hige amounts of products enter consumption that after this return period there will be more recycled product material that the new one. The difference lies in changing the amount of return or its intensity but as a matter of fact, return grows depends heavily on time frame. This growing return demonstrates itself in purchase of new products. This amount is quite high at the beginning - at first it is important to purchase new material at full amount, which is necessary for ensuring proper production. After certain time, this return will exceed material consumption and no new material purchase will be needed by the time this overproduction will have returned and purchase will have been renewed. Finally, purchase will remain at the level which equals to what has been liquidated (waste) in course of the whole process. The course of new material purchase is described below:

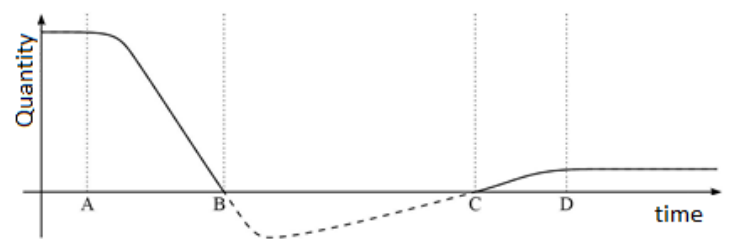

Figure 5

Process of purchase of a new material

Source: private source, 2019 
Point A refers to the place where products are slowly returned. A business uses only new material to ensure production at this level. From this point products are returned and production is ensured from that material which was obtained from recycled products and simultaneously, from new material until the point $\mathrm{B}$ when the company starts using only the material from returned products. Since not all products are returned and certain waste is generated through the whole process, material stock from return is gradually decreasing (the return level will oscillate around one stable level). Suddenly this stock has dropped to such a level that a business will have to restart purchase - the point C. From this point purchase will grow stable to reach a constant level and will equal to the number of products that have not returned to or ended up as waste from the whole process. In the point $\mathrm{D}$, a business purchases constant stock of products.

\subsection{The Modeling of Product Return in Time}

Prior to proper defining of the return model and its specific components, we have to clarify process dynamicity. It is all based upon the aforementioned mathematic programming, mainly optimisation by means of dynamic programming. The term "model“ is relatively overvalued in this case as is it not presented as an eco-eco model with a specific complex function and a defined extreme. It is only a mere calculation of return or a sort of model, which is the term used further in our paper. This calculation can often be only a part of complex models of mathematic programming or thanks to its dynamicity and stochastic initial variables it can be a part of simulating models. And these simulating models are much more common in this case. The table below shows flexibility of modeling. Specific columns represent the periods t. As we can see, purchase is influenced by collection at the end of the third period, which accounts for three fifths of the first period, i.e. the model can adapt to demand and product return as purchase for production in the fourth period has already been influenced by collection. We can also see that in its initial phase, purchase is influenced by collection (see the scheme below). Only after certain time periods, collection will start to influence purchase. Purchase can also be influenced remaining stock from previous periods, production or production stock level in the previous period and most of all, by sale in the previous time period.

Table 2

Course of a business process

\begin{tabular}{|c|c|c|c|c|c|c|c|c|c|}
\hline Period & $\mathbf{0}$ & $\mathbf{1}$ & $\mathbf{2}$ & $\mathbf{3}$ & $\mathbf{4}$ & $\mathbf{5}$ & $\mathbf{6}$ & $\mathbf{7}$ & $\mathbf{8}$ \\
\hline I. & N & V & P & Z & Z & Z & Z & Z & Z \\
\hline II. & & N & V & P & Z & Z & Z & Z & Z \\
\hline III. & & & N & V & P & Z & Z & Z & Z \\
\hline IV. & & & & N & V & P & Z & Z & Z \\
\hline
\end{tabular}

Legend: $N$ - Purchase, V-Production, P-Sale, Z - Collection Source: private sources, 2019 
For this reason, shortening periods contributes to better model flexibility and better defining of adaptation and model of demand and therefore, promotes cost optimisation linked to insufficient or excessive stock. The model, apart from cost optimisation by calculating optimal stock, can also define the course of purchase in time and therefore it enables us to determine the secondary goal, i.e. defining the strategy of purchase and the number of periods the company needs until its purchase remains stable on one level. It also provides room for determining this level as well as the amount of purchased material for the specific time period and thus helps the company get information about allocation of financial resources for purchase. From the viewpoint of financial allocation, this model is much more comfortable as it is not necessary to purchase large amounts of stock for longer periods but rather opt for smaller and more effective ones. The calculation model is demonstrated in the Picture 4 where the part a) shows regular return from one specific time period. On the contrary, the parts b) and c) describe growing return. It is assumed that so many products are returned into production after several time periods that within a certain time span, the material from recycled products will exceed new material. The difference between the pictures $b$ ) and c) is the change of either the return level or return intensity, but as a matter of fact, growing return depends heavily on a time span.

\subsection{Calculation Model for Growing Return}

In case of single return from the previous period as shown in the part a) below, its calculation is rather simple. The number of returned products in the period $t$ is determined by probability $P R(R)_{t}$, which states how many sold products are returned in the previous period $t-1$ for the period $t$. After that we are able to express the product return $\left(R_{t}\right.$, ) by the relation $R_{t}=P R(R)_{t} D_{(t-1)}$, pre $t=1,2$, $\ldots T$ where $D_{t-1}$ refers to sale of products in the period $t-1$. As far as growing return is concerned, we do not only refer to sale of products in the period $t-1$, but also for periods preceding the period $t$. Particular products are not indexed because of their general description still in reality, the number of products equals to $n$ and therefore demand can be defined for the aggregate $D_{i}$, where $i=1,2, \ldots n$. The table 2 below compares demand to sale as the table has been drawn up for the manufacturer. The calculation assumes that sale copies demand, which is stochastic.

\section{Variant 1}

There are various possibilities how to calculate the growing return. The simplest one is the first variant drawing from the total number of products which were sold in the specific period linked to probability of return. The original $P R(R)_{t}$ transforms into $P R(R x)_{t}$, where $x$ refers to the number of periods $t$ when the product is by a consumer, e.g. $P R(R 3)_{t}$ refers to probability for the product being returned in the third period of sale. For $x$ it is equal that from the interval 1 to $X, 1$ up to $X, x \in\langle 1 ; X\rangle$, where the upper value $X$ represents ,,a limit“ beyond which it 
is assumed the product will not return to its manufacturer and will end up as waste. Probability of return is slowly dropping as we assume that most of return is completed in the following period after sale and after that, the possibility for the product to be taken back is rather small. In this variant, the aggregate of probabilities is below 1 and it is, therefore, assumed that a certain percentage of products will never return to manufacturers and end up as waste. This percentage is determined by the difference between the sum of probabilities and the number 1 as probabilities are calculated from the total number of products that have been sold. Probability of return can be noted down as follows:

$R_{t}=P R(R 1)_{t} D_{(t-1)}+P R(R 2)_{t} D_{(t-2)}+\ldots+P R(R X)_{t} D_{(t-X)}$, for $t=1,2, \ldots T$ and $X$ - the number of return periods. This simple variant is described in the following case study which uses fictional numbers to explain the principle determining the return volume and illustrates the return calculation on random numbers.

\section{Variant 2}

The second variant is applied when probability $P R(R)_{t}$ remains unchanged but the return calculation is modified - it differs from the first variant because it does not take into account the total number of products having been sold within a particular time period rather from what has remained by a consumer in a given period. This index is much more complex, but more real-based as it does not refer to those products that have been returned from previous periods and therefore provides more precise data. It means that probability is linked to remaining products which stayed by a consumer from $X$ previous time periods plus all products which were sold in the immediately preceding period. This variant also calculates the limit $X$ beyond which it is supposed that the product will never be returned to its manufacturer and will be considered as waste. Probability $P R(R)_{t}$ has to be lower ${ }^{2}$ than 1 to ensure that after the $X$ time period the amount of goods remaining by a consumer is equal to waste. This return probability can be noted down as follows:

$R_{t}=$

$P R(R)_{t} D_{(t-1)}+P R(R)_{t}\left(1-P R(R)_{t}\right) D_{(t-2)}+P R(R)_{t}(1-$

$\left.P R(R)_{t}\right)^{2} D_{(t-3)}+\ldots+P R(R)\left(1-P R(R)_{t}\right)^{X-1} D_{(t-X)}$, for $t=1,2, \ldots T$ and $X-$ the number of return periods.

\section{Variant 3}

The third variant combines the previous two variants. As the second variant, it does not take into account return from the total number of products having been sold within particular time periods, but only the amount having remained by a consumer. This variant also calculates with ,a limit“ $X$, beyond which it is supposed the product will never return to its manufacturer and will end up as waste. At the same time, it defines return probability with a declining character. This decline is not so sharp as in the first variant as the return is supposed to drop gradually with the number of periods when the product is by a consumer. There is 
no assumption that the aggregate probabilities are below 1. Particular probabilities have to be lower than 1 but it does not suppose that a certain number of products will never return to a manufacturer and end up as waste. Such waste is, as in the first variant, determined by the limit $X$. This determination of return can be noted down as follows:

$$
\begin{aligned}
& R_{t}=P R(R 1)_{t} D_{(t-1)}+P R(R 2)_{t}\left(1-P R(R 1)_{t}\right) D_{(t-2)}+P R(R 3)_{t} \\
& \left(1-P R(R 2)_{t}\right)\left(1-P R(R 1)_{t}\right) D_{(t-3)}+\ldots+P R(R X)\left(1-P R(R(X-1))_{t}\right) \\
& \left(1-P R(R(X-2))_{t}\right) \ldots\left(1-P R\left(R(X-(X-1))_{t}\right)_{t} D_{(t-X)}\right. \\
& \text { for } t=1,2, \ldots T ; u=1,2, \ldots U ; X-\text { the number of return periods. }
\end{aligned}
$$

\subsection{Illustration of Calculation of Growing Return}

In case of a single return from the previous period as shown in the part a) below, its calculation is rather simple. The number of returned products in the period $t$ is

\section{Case Study 1}

Case study 1 is linked to the first variant and illustrates the calculation of return on random numbers oscillating around 1,000. It is supposed that the upper-value $X$ is five, so after the fifth year, the product does not return to its manufacturer and turns into waste. Probabilities in the example are: $P R O B(R 1)=0.5 ; P R(R 2)=$ $0.2 ; P R(R 3)=0.05 ; P R(R 4)=0.025 ; P R(R 5)=0.025$. The study suggests that $20 \%$ of products never return to manufacturers and turn into waste and the study is presented for one collection point and for one type of product. Return is calculated as follows:

$$
\begin{aligned}
& R_{t}=P R(R 1) D_{t-1}+P R(R 2) D_{t-2}+P R(R 3) D_{t-3}+P R(R 4) D_{t-4}+ \\
& P R(R 5) D_{t-5}, \text { for } t=1,2, \ldots T \text { and } X=5 .
\end{aligned}
$$

Table 3

Case study 1

\begin{tabular}{|l|r|r|r|r|r|r|r|r|}
\hline Period & I. & II. & III. & \multicolumn{1}{l|}{ IV. } & \multicolumn{1}{l|}{ V. } & \multicolumn{1}{l|}{ VI. } & \multicolumn{1}{l|}{ VII. } & VIII. \\
\hline & 1000 & 500 & 200 & 50 & 25 & 25 & 0 & 0 \\
\hline & & 980 & 490 & 196 & 49 & 24.5 & 24.5 & 0 \\
\hline & & & 1020 & 510 & 204 & 51 & 25.5 & 25.5 \\
\hline & & & & 1010 & 505 & 202 & 50.5 & 25.25 \\
\hline & & & & 970 & 485 & 194 & 48.5 \\
\hline & & & & & & 1000 & 500 & 200 \\
\hline & & & & & & & 1030 & 515 \\
\hline Amount sold & $\mathbf{1 0 0 0}$ & $\mathbf{9 8 0}$ & $\mathbf{1 0 2 0}$ & $\mathbf{1 0 1 0}$ & $\mathbf{9 7 0}$ & $\mathbf{1 0 0 0}$ & $\mathbf{1 0 3 0}$ & $\mathbf{1 0 1 0}$ \\
\hline Material return & $\mathbf{0}$ & $\mathbf{5 0 0}$ & $\mathbf{6 9 0}$ & $\mathbf{7 5 6}$ & $\mathbf{7 8 3}$ & $\mathbf{7 8 7 . 5}$ & $\mathbf{7 9 4 . 5}$ & $\mathbf{8 1 4 . 2 5}$ \\
\hline
\end{tabular}

Source: Private source 


\section{Case Study 2}

Case study 2 draws from the same assumptions as to the previous model while illustrating the calculation of return on random numbers oscillating around 1,000 and supposing that the upper-value $X$ is five, i.e. after the fifth year the product does not return to its manufacturer and turns into waste. The study is presented for one collection point and for one type of product. Probability $P R(R)=0.3$ and return is calculated as follows:

$$
\begin{aligned}
& R_{t}=P R(R) D_{t-1}+P R(R)(1-P R(R)) D_{t-2}+P R(R)(1-P R(R))^{2} D_{t-3}+ \\
& +P R(R)(1-P R(R))^{3} D_{t-4}+P R(R)(1-P R(R))^{4} D_{t-5}, \text { for } t=1,2, \ldots T \text { and } X \\
& =5 .
\end{aligned}
$$

Table 4

Case study 2

\begin{tabular}{|l|r|r|r|r|r|r|r|r|}
\hline Period & I. & II. & III. & IV. & V. & \multicolumn{1}{l|}{ VI. } & \multicolumn{1}{l|}{ VII. } & \multicolumn{1}{|l|}{ VIII. } \\
\hline & 1000 & 300 & 210 & 147 & 102.9 & 72.03 & 0 & 0 \\
\hline & & 980 & 294 & 205.8 & 144.06 & 100.84 & 70.59 & 0 \\
\hline & & & 1020 & 306 & 214.2 & 149.94 & 104.96 & 73.47 \\
\hline & & & & 1010 & 303 & 212.1 & 148.47 & 103.93 \\
\hline & & & & & 970 & 291 & 203.7 & 142.59 \\
\hline & & & & & & 1000 & 300 & 210 \\
\hline & & & & & & & 1030 & 309 \\
\hline Amount sold & $\mathbf{1 0 0 0}$ & $\mathbf{9 8 0}$ & $\mathbf{1 0 2 0}$ & $\mathbf{1 0 1 0}$ & $\mathbf{9 7 0}$ & $\mathbf{1 0 0 0}$ & $\mathbf{1 0 3 0}$ & $\mathbf{1 0 1 0}$ \\
\hline Material return & $\mathbf{0}$ & $\mathbf{3 0 0}$ & $\mathbf{5 0 4}$ & $\mathbf{6 5 8 . 8}$ & $\mathbf{7 6 4 . 1 6}$ & $\mathbf{8 2 5 . 9 1}$ & $\mathbf{8 2 7 . 7 2}$ & $\mathbf{8 3 8 . 9 9}$ \\
\hline
\end{tabular}

Source: Private source

\section{Case Study 3}

Case study 3 is based upon the same assumptions as to the previous two studies while illustrating the calculation of return on random numbers oscillating around 1,000 and supposing that the upper-value $X$ is five, i.e. after the fifth year the product does not return to its manufacturer but turns into waste. The study is presented for one collection point and for one type of product. Probabilities in the case study are as follows: $P R(R 1)=0.5 ; P R(R 2)=0.4 ; P R(R 3)=0.3 ; P R(R 4)=$ $0.2 ; P R(R 5)=0.1$. Return is calculated as follows:

$$
\begin{aligned}
& R_{t}=P R(R 1) D_{t-1}+P R(R 2)(1-P R(R 1)) D_{t-2}+P R(R 3)(1-P R(R 2)) \\
& (1-P R(R 1)) D_{t-3}+P R(R 4)(1-P R(R 3))(1-P R(R 2))(1-P R(R 1)) D_{t-4}+ \\
& +P R(R 5)(1-P R(R 4))(1-P R(R 3))(1-P R(R 2))(1-P R(R 1)) D_{t-5}
\end{aligned}
$$

for $t=1,2, \ldots T$ and $X=5$. 
Table 5

Case study 3

\begin{tabular}{|l|l|l|r|r|r|r|r|r|}
\hline Period & I. & II. & III. & IV. & V. & \multicolumn{1}{l|}{ VI. } & \multicolumn{1}{l|}{ VII. } & VIII. \\
\hline & 1000 & 500 & 200 & 90 & 42 & 16.8 & 0 & 0 \\
\hline & & 980 & 490 & 196 & 88.2 & 41.16 & 16.46 & 0 \\
\hline & & & 1020 & 510 & 204 & 91.8 & 42.84 & 17.17 \\
\hline & & & 1010 & 505 & 202 & 90.9 & 42.42 \\
\hline & & & & 970 & 485 & 194 & 87.3 \\
\hline & & & & & 1000 & 500 & 200 \\
\hline & & & & & & & 1030 & 515 \\
\hline & & & & & & & & 1010 \\
\hline Amount sold & $\mathbf{1 0 0 0}$ & $\mathbf{9 8 0}$ & $\mathbf{1 0 2 0}$ & $\mathbf{1 0 1 0}$ & $\mathbf{9 7 0}$ & $\mathbf{1 0 0 0}$ & $\mathbf{1 0 3 0}$ & $\mathbf{1 0 1 0}$ \\
\hline Material return & $\mathbf{0}$ & $\mathbf{5 0 0}$ & $\mathbf{6 9 0}$ & $\mathbf{7 9 6}$ & $\mathbf{8 3 9 . 2}$ & $\mathbf{8 3 6 . 7 6}$ & $\mathbf{8 4 4 . 2}$ & $\mathbf{8 6 1 . 8 9}$ \\
\hline
\end{tabular}

Source: Private source

\section{Conclusion}

As we have already mentioned before, current trends in consumer behaviour as well as legislation make businesses think environmentally friendly. This is why the paper points to possibilities of ecological orientation without increasing the economic burden on every day production processes. The main goal of the paper has been to provide practical modeling of eco-eco principles in the circular economy by offering a specific view of the model aspect of procurement of production material from recycling. Moreover, we were trying to define possibilities of how to meet eco-eco goals of businesses based upon the circular economy principles while keeping cost-effectivity and promoting an ecological footprint of the production process. In conclusion, it is important to say that the basis of economic and ecological models which, apart from optimising their purpose-made function, deal with minimising costs or maximising earnings or profits, and what is more, also have an environmental impact function.

This function mainly deals with the environmental impact of production processes and these are:

- minimising waste,

- minimising use of toxic materials,

- minimising negative impacts of product transport (emissions),

- dminimising use of energies.

This function is dependent on various factors and their relative significance as the environmental impact can be difficult to quantify and in reality, it is rather complicated to calculate its value. It can also be mentioned that the current state of the environment is alarming. A long-term consumption way of life of the whole society has resulted in various global ecological and economic problems which are 
becoming worse every day and are having a destructive impact on end users. The only perspective is transfer from the linear model to the circular one with the purpose of minimising waste and maximising product benefits. Some businesses have already become aware of their responsibility for the environment and have already started to implement these principles into their production processes. However, the implementation is one thing and communication of this positive change to consumers still remains a challenge. As this model is mainly theoretical and rather general, all depends on its application. The variant is suitable for products with high initial returnability, which means that most of them can return right after the sale. There are various ways how to calculate return or volume of material one can obtain by recycling products after their expiry.

The given examples can serve as a basis for more complex calculations for other specific products. Therefore, it is crucial to know the product features as well as the environment to which these products will be returned. Only on the basis of these data we may draw a particular calculation or adapt specific case studies hereto. These can finally serve as simulation models for product return. The illustrations show that return modeling or the volume of returned products for their further recycling have to be properly calculated. Example 1 presents the easiest calculation. It is only about a mere index, but real implementation into an eco-eco model is often faced with complications as it is not that obvious to draw probabilities for specific time periods as well as waste probability. Example 2 demonstrates the second variant of calculation, which is more likely to be used in practice, as it helps set average return probability. This variant is suitable for simulating eco-eco models dealing with modeling or return calculation. This index is dynamically changing and can adapt to the current market situation. Another advantage is the possibility to create several variants within one simulating model and its proper verification. The last variant combines the previous ones with an estimation of particular probabilities the aggregate of which equals 1 and calculates the amount of waste by means of a similar index as the second variant. This variant is suitable for mathematical programming or dynamic programming models. Probability helps us to derive balance for the aggregation principle of purpose-made criteria and their critical function.

This study merely explains the fundamentals of a theoretical model meaning it might only obtain specific limitations when applied to a specific scenario, but not in its fundamental nature. Thus, the limitations of this model are only casespecific and will not be discussed further.

\section{Acknowledgement}

This contribution is a partial result of the project VEGA 1/0078/18 Aspects of marketing communication in the management processes of the circular economy. 


\section{References}

[1] Adamisin P., Kotulic R., Mura L., Kravcakova Vozarova I., Vavrek R. (2018) Managerial approaches of environmental projects: an empirical study. Polish Journal of Management Studies, Volume 17, No. 1, pp. 27-38, ISSN 2081-7452

[2] Benešová, H. (2010) Environmental technologies and eco-innovations. I. issue. Prague: CENIA, 2010, 135 s. ISBN 978-80-85087-90-1

[3] Bod'ová, E., Gajarská, A., Bad’urová, D. (2004) Application of the Environmental Requirements in Everyday Products. In. Environment, Vol. 38, No. 4, 173-177, 2004, ISSN 0044-4863

[4] Brezina, I.; Čičková, Z.; Pekár, J.: Modeling aspects of reverse logistics, Quantitative Methods in Economics [Multiple Criteria Decision Making XIV] June 5-7, 2008, High Tatras, Slovak Republic

[5] Darnadyová, A. (2014) Circular Economy. In: Waste management. [Online]. August 2014, Available at: <http://www.odpadyportal.sk/Dokument/102210/kruhova-ekonomika-circular-economy.aspx>

[6] Dul’ová Spišáková, E., Mura, L., Gontkovičová, B., Hajduová, Z. (2017) R\&D in the context of Europe 2020 in selected countries. Economic Computation and Economic Cybernetics Studies and Research, Vol. 51, No. 4, pp. 243-261, ISSN 0424-267 X

[7] Durda, L., Kljucnikov, A. (2019) Social networks in entrepreneurial startups development. Economics \& Sociology, 12 (3), 192-208

[8] Dyckhoff, H.; Lackes, R.; Reese, J. (2003) Supply Chain Management and Reverse Logistics. Berlin : Springer, 2003, 426 s. ISBN 3-540-40491-0

[9] EIS.: Circular Economy as a path to economic growth. [online] Available at: <http://eurodenik.cz/ekonomika/kruhova-ekonomika-v-evrope-jakocesta-k-hospodarskemu-rustu> [07-06-2019]

[10] European Commission - Environment, [online] Available at: <http://ec.europa.eu/environment/waste/index.htm> [07-06-2019]

[11] European Commission - Environment, [online] Available at: <http://ec.europa.eu/environment/waste/legislation/index.htm>[07-06-019]

[12] Filimonova, I., Komarova, A., \& Mishenin, M. (2020) Impact of the global green factor on the capitalization of oil companies in Russia. Oeconomia Copernicana, 11(2), 309-324, https://doi.org/10.24136/oc.2020.013

[13] Fleischmann, m. et al. (1997) Quantitative models for reverse logistics: A review. European Journal of Operational Research, 103, 1-17, ISSN: 03772217

[14] Fleischmann, M. (2001) Quantitative models for reverse logistics. Rotterdam: Softcover, 181 s. ISBN: 978-3-540-41711-8 
[15] Gežík, P., Brezina, I. (2009) Reverse supply process and balance equations. In Utilization of quantitative methods in scientific research and practice IX Department of operations research and econometry FHI EU in Bratislava: [elektronický zdroj]. Bratislava : EKONOM, ISBN 978-80-225-2759-0, s. $1-7$

[16] Government Office of the Slovak Republic - Europe (2020) [online] Available at: <http://www.eu2020.gov.sk/europa-2020/> Evaluation of the implementation of the Europe 2020 strategy for smart, sustainable and inclusive growth. [online] Available at: < http://ec.europa.eu/europe2020/pdf/europe2020stocktaking_annex_sk.pdf>

[17] Guide, V. D. R. Jr. et al. (2000) Production planning and control for remanufacturing: industry practice and research needs. In Journal of Operations Management, Vol. 18, Issue 4, 2000. ISSN 0272-6963

[18] Hajduová, Z., Andrejkovič, M., Mura, L. Utilizing experiments designed results during error identification and improvement of business processes. In: Acta Polytechnica Hungarica, Vol. 11, No. 2, 2014, pp. 149-166, ISSN $1785-8860$

[19] Horecký, J. (2018) Operation and action of a trade union (in terms of Czech Republic labour law). Central European Journal of Labour Law and Personnel Management, 1 (1), 17-27, http://doi.org/10.33382 /cejllpm.2018.01.02

[20] Jašková, D. (2019) Assessment of social development in Slovakia in the context of human resources. Central European Journal of Labour Law and Personnel Management, 2 (2), 21-32, doi: 10.33382/cejllpm.2019.03.02

[21] Krykavskyy, Y., Pokhylchenko, O., \& Hayvanovych, N. (2019) Supply chain development drivers in industry 4.0 in Ukrainian enterprises. Oeconomia Copernicana, 10(2), 273-290

[22] Mesterházy, Á.; Oláh, J.; Popp, J. Losses in the Grain Supply Chain: Causes and Solutions. Sustainability 2020, 12, 2342

[23] Mucha, B., Brestovanska, P., Peracek, T. (2018) Using the Correct Sampling Method as a Prerequisite for a Successful Financial Audit. $31^{\text {st }}$ International Business Information Management Association (IBIMA) Conference, International Conference Proceedings, pp. 3503-3511, ISBN 978-0-9998551-0-2

[24] Mura, L., Havierniková, K, Machová, R. (2017) Empirical results of entrepreneurs' network: Case study of Slovakia. Serbian Journal of Management, Vol. 12, No. 1, pp. 121-131

[25] Nascimento, DLM., Alencastro, V., Quelhas, OLG., Caiado, RGG., GarzaReyes, JA., Lona, LR., Tortorella, G. (2019) Exploring Industry 4.0 technologies to enable circular economy practices in a manufacturing 
context A business model proposal. Journal of Manufacturing Technology Management, 30 (3), 607-627 SI

[26] Judit Oláh, György Karmazin, Károly Pető, József Popp (2018) Information technology developments of logistics service providers in Hungary, International Journal of Logistics Research and Applications, 21:3, 332344, DOI: $10.1080 / 13675567.2017 .1393506$

[27] Peracek, T., Noskova, M., Mucha, B. (2018) Selected issues of Slovak business environment. $24^{\text {th }}$ International Scientific Conference on Economic and Social Development - Managerial Issues in Modern Business, International Conference Proceedings, pp. 254-259

[28] Radu, L. D. (2018) Green ICT: some challenges and potential solutions. Acta Oeconomica Universitatis Selye 7 (2), 141-150

[29] Razminiene, K. (2019) Circular economy in clusters' performance evaluation. Equilibrium. Quarterly Journal of Economics and Economic Policy, 14(3), 537-559, https://doi.org/10.24136/eq.2019.026

[30] Selvefors, A., Rexfelt, O., Renstrom, S., Stromberg, H. (2019) Use to use A user perspective on product circularity. Journal of Cleaner Production, $223,1014-1028$

[31] Schulz, T., Ferretti, I. (2008) On the alignment of lot sizing decisions in a remanufacturing system in the presence of random yield : Working Paper No. 34, Magdenburg : Faculty of Economics and Management Magdenburg, 2008

[32] Srovnalíková, P., Semionovaitè, E., Baranskaitè, E., Labanauskaitė, D. (2020) Evaluation of the Impact of Sharing Economy on Hotel Business. Journal of Tourism and Services, 20(11), 150-169

[33] Stasiak-Betlejewska, R. (2015) Clusters as the element of eco-innovations promoting in the European construction on the Polish example. Acta Oeconomica Universitatis Selye 4 (2), 182-197

[34] Zaušková, A., Rezníčková, M. (2020) SoLoMo marketing as a global tool for enhancing awareness of eco-innovations in Slovak business environment. Equilibrium. Quarterly Journal of Economics and Economic Policy, 15(1), 133-150, https://doi.org/10.24136/eq.2020.007 